\title{
Coexisting renal cell carcinoma and renal artery aneurysm: A case report and literature review
}

\author{
ZIJIAN WANG ${ }^{1}$, WEI XIONG ${ }^{1}$, CIZHONG PAN $^{1}$, LIANG ZHU $^{1}$, PAN WANG $^{2}$, \\ XINJUN WANG ${ }^{1}$, ZHICHAO HUANG ${ }^{1}$, XIAOKUN ZHAO ${ }^{1}$ and ZHAOHUI ZHONG ${ }^{1}$ \\ ${ }^{1}$ Department of Urology, The Second Xiangya Hospital, Central South University, Changsha, Hunan 410011; \\ ${ }^{2}$ Department of Pathology, Affiliated Hospital of Hebei University, Baoding, Hebei 071000, P.R. China
}

Received October 6, 2014; Accepted December 22, 2014

DOI: $10.3892 / \mathrm{etm} .2015 .2390$

\begin{abstract}
Renal artery aneurysms (RAAs) are a rare condition; however, the coexistence of an RAA with renal cell carcinoma (RCC) is extremely rare. The present study reports the case of a patient found to simultaneously have an operable RAA and RCC. The patient was treated by radical nephrectomy. Surgical intervention for RAA is controversial, and the appropriate treatment for RCC with RAA has not been well characterized and requires further study. The present study reports the examination of a patient with coexisting RAA and RCC and suggests possible treatments for this condition. In addition, a review of the English literature investigating the association of RCC with RAA is presented.
\end{abstract}

\section{Introduction}

Renal artery aneurysms (RAAs) are a rare condition, with an incidence rate of $0.01-1 \%$, based on autopsy results and previous angiographical studies (1). RAA risk factors include atherosclerosis, fibrodysplasia, arteritis, trauma and neurofibromatosis (2). The lesions are generally asymptomatic and incidentally found during investigations performed for different reasons (3). According to the size of the aneurysm and clinical presentation, various management options may be selected, such as observation or surgical intervention, including aneurysmectomy and repair of RAA. Nephron-sparing surgery has a similar outcome with radical nephrectomy for localized renal cell carcinoma (RCC) (4). Coexistence of RCC and RAA in a single patient is extremely rare. To the best of our knowledge, only three cases of RCC with ipsilateral RAA have been reported $(5,6)$, with the patients receiving different treatment to patients with RCC and contralateral RAA (7).

Correspondence to: Professor Xiaokun Zhao, Department of Urology, The Second Xiangya Hospital, Central South University, 139 Renmin Road, Changsha, Hunan 410011, P.R. China

E-mail: xiaokunzhao@126.com

Key words: renal artery aneurysms, renal cell carcinoma, radical nephrectomy
The present study reports the case of a 57-year-old patient who exhibited a simultaneous operable RAA and RCC. In addition, the study discusses possible suggestions for the treatment of this condition.

\section{Case report}

A 57-year-old male patient was referred to the Second Xiangya Hospital of Central South University (Changsha, China) complaining of an abdominal pain that had persisted for four days. The patient was otherwise healthy and denied any history of trauma. Blood pressure and other physical examination results were normal. In addition, laboratory tests showed normal levels of blood urea nitrogen and creatinine, and urinalysis was normal. A computed tomography (CT) scan revealed a $3.2 \times 3.3 \mathrm{~cm}^{2}$ solid mass in the upper pole of the right kidney and a $2.2 \times 2.0 \mathrm{~cm}^{2}$ fusiform aneurysm near the renal hilum (Fig. 1A). CT angiography confirmed the diagnosis of an RAA (Fig. 1B).

Informed consent was obtained from the patient prior to surgery. A laparoscopic radical nephrectomy was subsequently performed. Gross specimen examination following surgery confirmed a $2.6 \times 2.3 \mathrm{~cm}^{2}$ aneurysm near the renal hilum, originating at the first bifurcation, and a $3.0 \times 3.5 \mathrm{~cm}^{2}$ renal mass. Pathological examination revealed the mass to be RCC (clear cell type, TlaN0M0 staged) and the aneurysm to be a true aneurysm (Fig. 2). The patient was followed-up with renal function examinations and ultrasound scans every three months, without any further treatment after surgery. At 12 months post-treatment, the patient was shown to be free of local recurrence or metastasis

\section{Discussion}

The exact incidence rate of RAA remains unknown; however, according to previous studies the incidence rate is $\sim 0.01 \%$ in the general population (8). Causes of an RAA include atherosclerosis, fibrodysplasia, arteritis, trauma and neurofibromatosis (2). Patients with an RAA may be asymptomatic or present with a variety of symptoms. The majority of patients present with hypertension and flank pain, and hematuria is exhibited in certain cases. However, in the present case, abdominal pain was the only symptom. 
Table I. Association between RAA and RCC in previous studies.

\begin{tabular}{lcllllr}
\hline Reference & $\begin{array}{c}\text { Age } \\
\text { (years) }\end{array}$ & Gender & $\begin{array}{c}\text { Location of } \\
\text { RAA and RCC }\end{array}$ & Symptom & \multicolumn{1}{c}{ Treatment } & Prognosis \\
\hline 5 & 49 & Male & Ipsilateral & Hypertension & Radical nephrectomy & Survival \\
6 & 56 & Male & Ipsilateral & Hypertension & Radical nephrectomy & Survival \\
6 & 70 & Female & Ipsilateral & Hypertension & Radical nephrectomy & Survival \\
7 & 47 & Male & Contralateral & Hypertension & Radical nephrectomy and & Survival \\
& & & & & contralateral aneurysmectomy & \\
\hline
\end{tabular}

RAA, renal artery aneurysm; RCC, renal cell carcinoma.
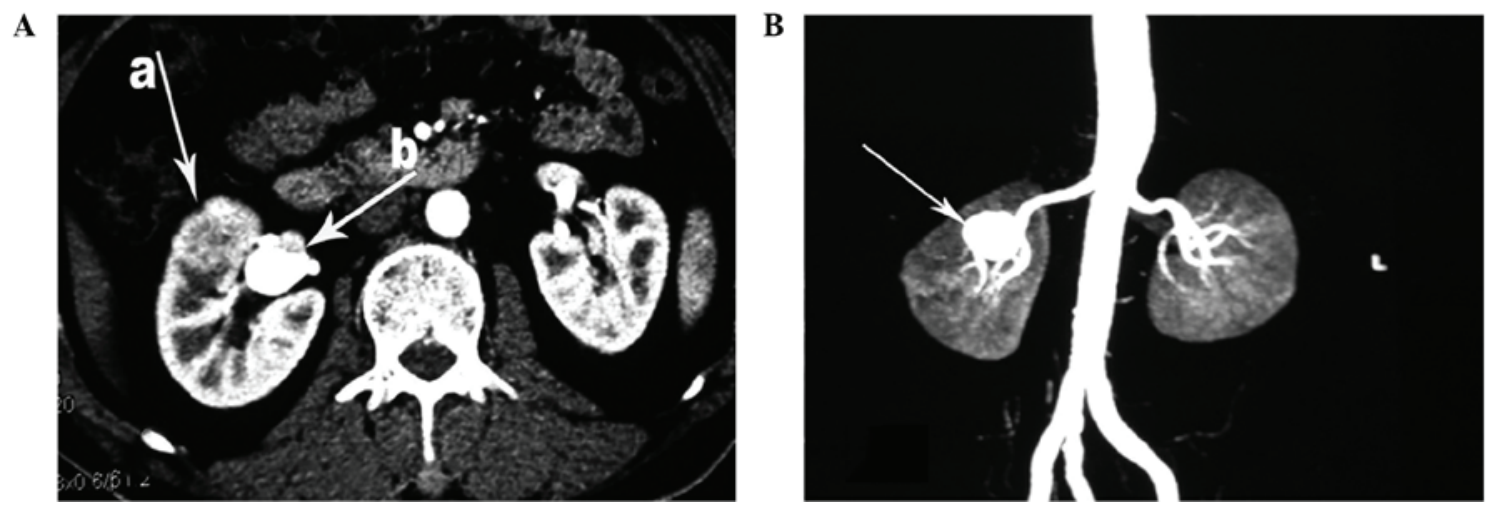

Figure 1. (A) Computed tomography (CT) scan showed a solid mass in the right kidney (arrow a) and a renal artery aneurysm (RAA; arrow b). (B) RAA was confirmed by CT angiography.

A

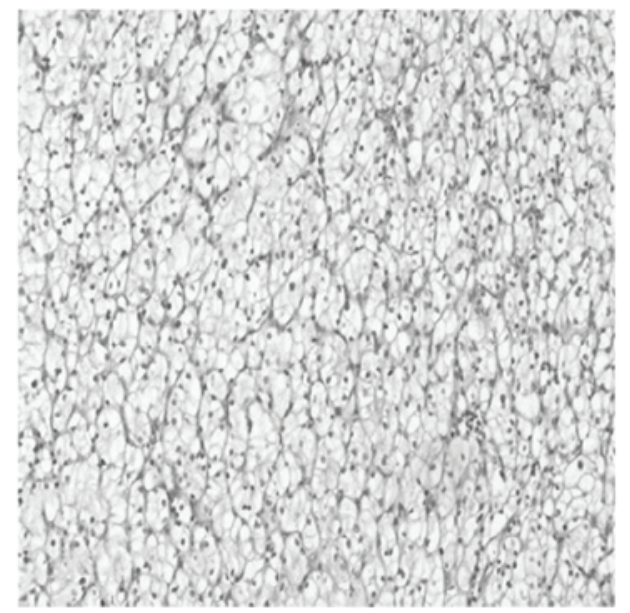

B

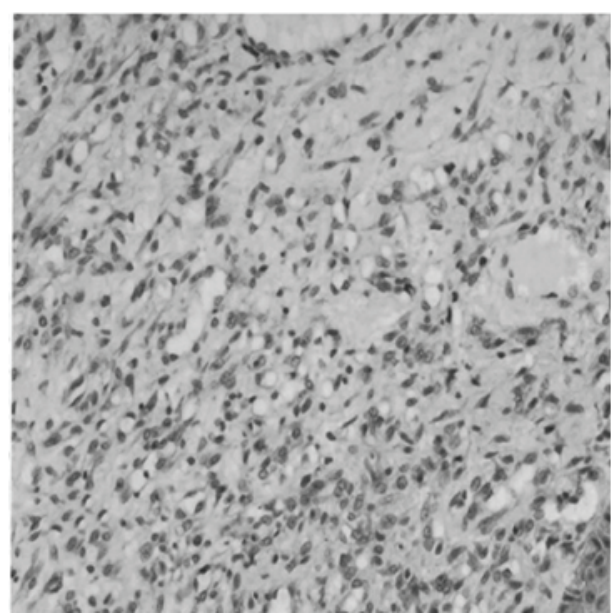

Figure 2. Pathology of the (A) renal cell carcinoma and (B) renal artery aneurysm (hematoxylin and eosin; magnification, x100).

There are numerous options for the treatment of RAAs, including observation, surgical and endovascular repair, and radical or partial nephrectomy. Asymptomatic patients with an aneurysm of $<2 \mathrm{~cm}$ in diameter may have their treatment followed by radiographic examination (2). The appropriate surgical intervention for RAAs remains controversial. Generally, aneurysms of $>2 \mathrm{~cm}$ in diameter, with symptoms including flank pain, hematuria or hypertension, are regarded as cause for surgical intervention (9). The main surgical interventions for an RAA include aneurysmectomy with primary closure or patch angioplasty, revascularization and embolization. Complicated intrarenal aneurysms may require an ex vivo procedure with arterial revascularization and autotransplantation of the kidney.

Coexistence of RCC and an RAA in a single patient is very rare; thus, few approaches for the treatment of this condition have been described. Hafez et al reported a series of 48 patients with RCC and renal artery disease (RAD) over a 30-year period; however, only two cases presented with RCC and RAA simultaneously (10). In order to improve the understanding of 
the management of patients with simultaneous RCC and RAA, a review of the English literature was conducted using the PubMed database. However, only four cases were ultimately identified (5-7), as shown in Table I.

All four cases had a history of hypertension, and one patient had a history of trauma. Three out of the four cases had ipsilateral RCC and RAA and were treated with radical nephrectomy. The fourth case exhibited RCC with contralateral RAA, and was treated with a radical nephrectomy and contralateral aneurysmectomy. The outcomes of all four cases were favorable.

In the present case, the RCC was relatively small $\left(3.2 \times 3.3 \mathrm{~cm}^{2}\right)$, which indicated a good operative outcome. In addition, the RAA was relatively large $\left(2.2 \times 2.0 \mathrm{~cm}^{2}\right)$, which according to the aforementioned criteria, required surgical intervention. Two surgical approaches were proposed, partial nephrectomy with RAA repair and radical nephrectomy.

In the majority of patients with RCC and RAD, nephron-sparing surgery is considered to be the best approach and several studies have demonstrated excellent clinical results $(11,12)$. One retrospective study indicated that RAA repair is feasible and safe (13). However, the total ischemia time of RAA recovery ranges between 60 and $155 \mathrm{~min}$ (median, $70 \mathrm{~min}$ ) and is even longer ex vivo (range, 140-450 min; median, $302 \mathrm{~min}$ ) due to the complexity of the procedure (13).

In the present case, a partial nephrectomy may have considerably increased the duration of the procedure and the risk of an unfavorable patient outcome. In order to avoid this risk, and in consideration of the patient's strong contralateral renal function, a radical nephrectomy was performed. The patient remained healthy one year after surgery, with no indications of metastasis or deficient renal function.

In conclusion, the incidence rate of simultaneous RCC with an RAA is very low. To the best of our knowledge, there are only three reported cases of RCC with ipsilateral RAA in English literature. There are no medical guidelines or recommendations for this condition. Radical nephrectomy appears to be the most practical approach at present; however, further research is required into the efficacy of the various treatment options for this rare condition.

\section{References}

1. Fleshner NE and Johnston KW: Repair of an autotransplant renal artery aneurysm: case report and literature review. J Urol 148: 389-391, 1992.

2. Novick AC: Management of renovascular disease. A surgical perspective. Circulation 83 (2 Suppl): I167-I171, 1991.

3. Ferrante A, Di Stasi C, Pierconti F and Snide F: Incidental finding of right renal venous aneurysm in a patient with symptomatic ipsilateral renal carcinoma: a case report. Cardiovasc Pathol 14: 327-330, 2005.

4. Ghavamian R and Zincke H: Open surgical partial nephrectomy. Sem Urol Oncol 19: 103-113, 2001

5. Casillas RA, Romero L and Virgilio C: Coexisting renal cell carcinoma and renal artery aneurysm. Ann Vasc Surg 16: 353-357, 2002.

6. Selli C,Carini M, Turini D and Schifano A: Renal cell carcinoma associated with renal artery aneurysm. Report of two cases. Urol Int 38: 374-377, 1983.

7. Ichiyanagi $\mathrm{O}$, Ishigooka M, Suzuki Y, et al: Renal cell carcinoma with renal artery aneurysm. Int Urol Nephrol 30: 385-390, 1998.

8. Hageman JH, Smith RF, Szilagyi E and Elliot JP: Aneurysms of the renal artery: problems of prognosis and surgical management. Surgery 84: 563-572, 1978.

9. Bastounis E, Pikoulis E, Georgopoulos S, et al: Surgery for renal artery aneurysms: a combined series of two large centers. Eur Urol 33: 22-27, 1998.

10. Hafez KS, Krishnamurthi V, Campbell SC and Novick AC: Contemporary management of renal cell carcinoma with coexistent renal artery disease: update of the Cleveland Clinic experience. Urology 56: 382-386, 2000.

11. Hafez KS, Novick AC and Campbell SC: Patterns of tumor recurrence and guidelines for followup after nephron sparing surgery for sporadic renal cell carcinoma. J Urol 157: 2067-2070, 1997.

12. Lerner SE, Hawkins CA, Blute ML, et al: Disease outcome in patients with low stage renal cell carcinoma treated with nephron sparing or radical surgery. J Urol 155: 1868-1873, 1996.

13. Seki T, Koyanagi T, Togashi M, et al: Experience with revascularizing renal artery aneurysms: is it feasible, safe and worth attempting? J Urol 158: 357-362, 1997. 